\title{
Construção imagético-discursiva da beleza corporal em mídias sociais: repercussões na percepção sobre o corpo e o comer dos seguidores
}

\section{Image-discursive construction of body beauty in social media: effects on followers' body and eating perceptions}

\author{
Ana Flávia de Sousa Silva' \\ Letícia dos Santos Neves \\ Camila Cremonezi Japur ${ }^{3,5}$ \\ Thais Rodrigues Penaforte ${ }^{4}$ \\ Fernanda Rodrigues de \\ Oliveira Penaforte ${ }^{1,2,5}$
}

\footnotetext{
' Universidade Federal do Triângulo Mineiro, Instituto de Educação, Letras, Artes, Ciências Humanas e Sociais, Programa de Pós-graduação em Psicologia. Uberaba, MG, Brasil.

${ }^{2}$ Universidade Federal do Triângulo Mineiro, Instituto de Ciências da Saúde, Curso de Nutrição. Uberaba, MG, Brasil.

${ }^{3}$ Universidade Federal de Uberlândia, Curso de Nutrição. Uberlândia, MG, Brasil.

${ }^{4}$ Universidade Federal da Bahia, Faculdade de Farmácia. Salvador, BA, Brasil.

${ }^{5}$ Universidade de São Paulo, Faculdade de Medicina de Ribeirão Preto, Curso de Nutrição e Metabolismo, Laboratório de Práticas e Comportamento Alimentares. Ribeirão Preto, SP, Brasil.
}

Correspondência / Correspondence Fernanda Rodrigues de Oliveira Penaforte E-mail: fernandapenaforte@yahoo.com.br

\section{Resumo}

As representações contemporâneas dos padrões de beleza se fecham em um corpo magro e delicadamente esculpido, e são especialmente disseminadas pelas redes sociais. O Instagram, com sua forte característica imagética, é muito utilizado para compartilhar imagens fitness, que difundem modelos corporais ideais. Este estudo, pautado na abordagem qualitativa, examinou o conteúdo dos comentários associados a fotos centradas na exposição corporal, veiculadas em um perfil fitness do Instagram. Foram selecionadas 12 fotos, publicadas entre janeiro a dezembro de 2017. Os comentários associados às fotos foram submetidos à análise de conteúdo, da qual emergiram três categorias de análise: "Maravilhosa, deusa, diva, inspiração": a exaltação ao corpo magro; "Meu sonho é ter esse corpo": o desejo de metamorfose corporal; e "Uma escolha errada arruína o corpo inteiro": culpabilização e distorções na relação alimentar. Observou-se íntima relação entre magreza, beleza, felicidade e como fonte de inspiração e desejo. Sob este prisma, existe um forte anseio de (re)construção do corpo, que se confunde com o anseio de (re)construção da própria identidade. Ainda, criase a ilusão de que o modelo de corpo ideal difundido está ao alcance de todos, bastando empenho, dedicação e força de vontade para alcançá-lo; ao mesmo tempo, sentimentos de tristeza e frustração emergem quando esse ideal não é atingido. Foi possível observar também que o desejo de remodelamento corporal reverbera na relação com a alimentação, que se torna distorcida e fonte de culpa, arrependimento e necessidade de controle do prazer, podendo culminar em comportamentos alimentares disfuncionais.

Palavras-chave: Redes sociais. Imagem corporal. Comportamento alimentar. 


\section{Abstract}

Contemporary representations of beauty patterns are limited to a lean and sculpted body. Such representations are mainly outspread by social media. Instagram, and its strong imaging profile, is widely used to share fitness images that depict idealbody models. The current study followed the qualitative approach to assess comments about body-exposure pictures in an Instagram fitness profile. Twelve pictures published between January and December 2017 were selected for the study. Comments about the pictures were subjected to content analysis. Three categories of analysis emerged from them: "Marvelous, goddess, diva, inspiration" - exaltation to the lean body; "My dream is to have this body"- desire for bodily metamorphosis; and "A wrong choice ruins the whole body"blame and distortions in food relations. There was close association among thinness, beauty and happiness as inspiration and desire sources. In light of the foregoing, one can assume the existing strong desire for bodily re-construction, which gets mixed with the sense of longing for the re-construction of one's identity. There is the illusion that the outspread image of an ideal-body model is available to all, as long as the individual works out hard, dedicates him/herself to it and has the strong will to reach such model. At the same time, this search for the ideal body raises feelings of sadness and frustration when this model is not reached. The desire for bodily remodeling echoes on eating habits, which become distorted and lead to guilt, regret and to the need of pleasure control. Such process can end up in dysfunctional eating behaviors.

Keywords: Social media. Body image. Eating behavior.

\section{Introdução}

Mudanças no contexto sócio-histórico fizeram com que o corpo magro, antes visto como sinal de escassez de alimentos e de fraqueza, passasse a ser valorizado como modelo dominante, tornando-se objeto de busca e desejo de todos, independentemente de classe, etnia, gênero ou geração. ${ }^{1}$ Ao mesmo tempo, o corpo gordo, que antes simbolizava fartura, riqueza e abundância, é hoje rejeitado e estigmatizado ${ }^{2}$ frente à beleza ideal e inquestionável da magreza. ${ }^{3}$

Uma característica das sociedades é definir categorias acerca dos atributos considerados normais ou comuns do ser humano, criando uma identidade social; o indivíduo que possui características desviantes desses atributos é considerado portador de um estigma. Diante disso, o indivíduo 
estigmatizado é aquele cuja identidade social inclui qualquer atributo que frustre as expectativas de normalidade observadas pela sociedade em questão. ${ }^{4}$ A sociedade contemporânea atribui crenças, valores e estigmas negativos ao indivíduo que possui um corpo gordo, e essa característica acaba se convertendo em uma marca social, moral e identitária indesejável, que desqualifica os sujeitos pelo simples fato de não estarem enquadrados nos padrões de aparência atuais. ${ }^{5}$

Adicionalmente, o atual cenário epidemiológico nacional e internacional aponta para números alarmantes de sobrepeso e obesidade. ${ }^{6}$ Esse quadro reforça, através de seu viés patológico, uma normativa para um tipo físico específico, que escapa a uma escolha individual de seu próprio corpo. $\mathrm{O}$ arquétipo do corpo saudável, que encontra seu signo no corpo magro, induz tanto uma pedagogia quanto uma ação clínica, voltada para a magreza. Nesse sentido, o corpo se configura como um espaço simbólico e passa a ser um instrumento da construção de identidade, sendo alvo de dominação e controle ao prescrever normas de conduta e valores, muito influenciado pelas imposições sociais. ${ }^{7}$

A mídia, dentre as fontes de imposições sociais, exerce papel fundamental na disseminação de modelos corporais e de padrões de beleza ${ }^{8}$ que se fecham exclusivamente em um corpo magro, moldado a suaves curvas e trabalhado esculturalmente em academia. ${ }^{3}$ Nessa perspectiva, a influência da mídia é considerada um dos principais fatores de risco para a insatisfação corporal, que por sua vez repercute de forma negativa na vida dos sujeitos, gerando frustração, culpa, vergonha, depressão, baixa autoestima e redução da qualidade de vida, além de ser um dos principais fatores de risco para o desenvolvimento de transtornos alimentares. ${ }^{8}$

Todavia, apesar da relação entre a mídia tradicional, como televisão e revistas, e a percepção e satisfação corporal já estar bem estabelecida, ${ }^{8}$ com o advento da internet, e mais especificamente com o surgimento das redes sociais, mudanças expressivas ocorreram neste contexto e a mídia nunca foi tão persuasiva como nos tempos atuais. Apesar de ser um fenômeno recente, os números das redes sociais nos revelam a dimensão já alcançada por esses serviços no contexto da internet. O Facebook conta com dois bilhões de usuários em todo o mundo, e o Instagram compartilha mais de 80 milhões de fotos diariamente pelos seus usuários. ${ }^{9}$

A natureza centrada na imagem faz do Instagram uma rede social diferenciada, considerando que as imagens são mais suscetíveis de serem lembradas do que as palavras. ${ }^{10}$ Nesse contexto, o Instagram torna-se ideal para o compartilhamento de imagens de conteúdo fitness, especialmente imagens de corpos magros e esbeltos, o que pode explicar a escolha desta plataforma pela comunidade fitness. ${ }^{11}$ Além de imagens corporais, nesta rede social, os adeptos do mundo fitness postam também regularmente fotos de suas comidas e dietas, o que pode impactar as escolhas alimentares dos seus usuários, através da influência social. Tal influência se refere ao impacto das pessoas sobre o comportamento alimentar de terceiros, podendo ser direto, indireto, consciente ou subconsciente. ${ }^{12}$ 
Entende-se que a ampliação do conhecimento acerca das repercussões de determinados conteúdos divulgados no Instagram, especialmente aqueles que disseminam e reforçam a necessidade do corpo magro como única possibilidade de corpo belo e adequado, é importante para a melhor compreensão desse fenômeno. E, por se tratar de um fenômeno relativamente novo, são pouco numerosos os estudos nessa temática, notadamente no cenário nacional. Nesse sentido, este estudo teve como objetivo examinar o conteúdo dos discursos associados a fotos que privilegiem a exposição corporal, veiculadas em um perfil fitness do Instagram.

\section{Método}

Trata-se de uma pesquisa de caráter exploratório, conduzida sob o enfoque qualitativo. Os métodos qualitativos são apropriados quando o fenômeno em estudo é complexo, de natureza social e não tende à quantificação. Para apreender métodos qualitativos, é preciso aprender a observar, registrar e analisar interações reais entre pessoas, e entre pessoas e sistemas, considerando o espaço social onde são construídas. ${ }^{13}$

Para este estudo, foram analisados os comentários publicados em fotos, cujo conteúdo imagético estava centrado na exposição corporal, de um perfil fitness da rede social Instagram. Nesta plataforma, os usuários comumente mantêm seu perfil público, permitindo que as pessoas sigam perfis, exponham e sejam expostos a fotos cujos donos, muitas vezes, não se conhecem pessoalmente. ${ }^{14}$

A escolha do perfil fitness, cujas fotos/comentários foram selecionados e analisados, ocorreu de forma intencional. Optou-se pela escolha de um perfil nacional com elevado número de seguidores, dentro da categoria fitness (mais de 3,8 milhões), e que expõe em suas publicações diárias referências de imagens corporais, padrões de alimentação e de atividade física.

A seleção das fotos, para a avaliação dos seus respectivos comentários, ocorreu em duas etapas. Na primeira etapa, os critérios adotados para a seleção foram: (1) fotos publicadas entre janeiro a dezembro de 2017; (2) fotos cujo conteúdo imagético fosse centrado na exposição corporal; e (3) fotos nas quais a blogueira aparecia sozinha. A seleção das fotos foi feita por dois avaliadores independentes, visando garantir a confiabilidade dessa seleção. Em caso de discordância entre os avaliadores quanto à seleção, havia uma avaliação por um terceiro avaliador. Na segunda etapa, devido ao elevado volume de fotos publicadas, optou-se por restringir a triagem a uma foto por mês, para análise dos seus comentários, perfazendo um total de 12 fotos, que compuseram o corpus analítico do estudo. A foto referente a cada mês foi selecionada com base no maior número de "curtidas" obtido. O conjunto das fotos que foram analisadas está descrito na tabela 1. 
Tabela 1. Características das fotos selecionadas para análise, Brasil, 2017 ( $\mathrm{N}=12)$.

\begin{tabular}{cccc}
\hline Identificação da foto & Mês & No. de curtidas & No. de comentários \\
\hline Foto 1 & Janeiro & 129.972 & 1.007 \\
Foto 2 & Fevereiro & 95.366 & 1.160 \\
Foto 3 & Março & 97.754 & 569 \\
Foto 4 & Abril & 170.144 & 2.656 \\
Foto 5 & Maio & 206.841 & 2.000 \\
Foto 6 & Junho & 128.168 & 620 \\
Foto 7 & Julho & 188.140 & 1.165 \\
Foto 8 & Agosto & 125.913 & 811 \\
Foto 9 & Setembro & 135.116 & 546 \\
Foto 10 & Outubro & 118.888 & 809 \\
Foto 11 & Novembro & 175.277 & 820 \\
Foto 12 & Dezembro & 155.581 & 728 \\
\hline
\end{tabular}

Os comentários veiculados nas fotos selecionadas na etapa anterior foram analisados por meio da análise do conteúdo, ${ }^{15}$ utilizando a técnica da análise temática, que compreende as seguintes etapas: (a) pré-análise; (b) exploração do material; e (c) tratamento dos dados obtidos e interpretação. Na pré-análise, todos os comentários foram lidos exaustivamente, o que tem por denominação "leitura flutuante", permitindo que as primeiras impressões e hipóteses relacionadas ao tema emerjam. Foram excluídos os comentários que não guardavam relação com a foto, e o conteúdo de interesse foi organizado dentro dos eixos temáticos, que foram definidos a posteriori.

Essa organização forneceu, por condensação, uma representação simplificada dos dados brutos, visando facilitar a compreensão das mensagens obtidas nas fotos. Em seguida, foi realizado o agrupamento das mensagens com características comuns em categorias a partir deste conteúdo organizado. Terminada a exploração do material, três categorias de análise emergiram: a) as que se referem à exaltação do corpo magro; b) relativas ao desejo de metamorfose do corpo; e c) manifestações de desmerecimento e culpabilização em relação à alimentação.

A última etapa do processo de análise diz respeito à interpretação. Esse tipo de análise corresponde a um conjunto de técnicas de análise das comunicações que visa, através de procedimentos sistemáticos e objetivos de descrição do conteúdo das mensagens, obter indicadores, 
quantitativos ou não, que permitam a inferência de conhecimentos relativos às condições de produção/recepção dessas mensagens..$^{15}$ Para fundamentar a discussão dos resultados, foram utilizados artigos científicos com base na literatura nacional e internacional sobre o tema.

\section{Resultados e Discussão}

\section{Categoria 1 - "Maravilhosa, deusa, diva, inspiração": a exaltação ao corpo magro}

As redes sociais são parte importante da vida da população contemporânea, e apesar de recentes, disseminam fortes valores e normas de padrões estéticos que são incorporados pela sociedade, transmitindo e reforçando ideais sociais relacionados ao corpo. ${ }^{16}$

A comunicação é uma performance, um jogo da informação; deste modo, quando permitimos que um indivíduo projete determinada situação, os receptores, ainda que seu papel pareça passivo, também projetarão de maneira efetiva outra situação em virtude da resposta recebida. ${ }^{17}$ Assim, a disseminação generalizada do ideal do magro como belo, principalmente por estímulos midiáticos, proporciona um mecanismo de constituição e aprendizagem para novos padrões culturais. ${ }^{18}$

A restrição na referência central do corpo magro não abarca a pluralidade corporal que coabita o mundo contemporâneo $;{ }^{19}$ no entanto, é uma estratégia de persuasão. E sobre figuras públicas, dotadas de grande poder de influência, se materializa um hedonismo imaginativo distante da realidade da maioria das pessoas, ${ }^{20}$ que simboliza o alcance do sucesso, controle, racionalidade, saúde e felicidade, e ainda uma qualidade moral. ${ }^{21} \mathrm{E}$ as mensagens, que incitam repetidamente a valorização do corpo magro, favorecem a internalização dessas mensagens como definitivas em relação às definições sociais de atratividade e beleza. ${ }^{22}$

Nesse sentido, os indivíduos expostos a esse padrão estético acreditam que alcançando esse modelo de corpo conseguirão também alcançar todas as qualidades que lhes são associadas. ${ }^{21} \mathrm{~A}$ atual sociedade dissemina, através de mecanismos subjetivos, uma ideia homogeneizada em relação à visão do que seria um corpo bonito. Nesse contexto, podemos refletir sobre a indústria e os serviços associados à beleza do corpo, pois estes projetam diversos métodos, técnicas e abordagens para o belo e magro. ${ }^{23}$ Desse modo, essa sociedade capitalista de indústrias "vende" a ideia de que, adquirindo meios para se enquadrar no padrão corporal, o indivíduo também está adquirindo a felicidade. ${ }^{24} \mathrm{E}$ não se trata de um projeto apenas para quem se encontra com sobrepeso ou obesidade; a perseguição pela magreza possui, atualmente, um caráter universal. Para além do emagrecimento, a necessidade de modelar a silhueta tornou-se um imperativo central na vida de muitos sujeitos, cuja principal motivação está pautada na estética. ${ }^{19}$ As expressões "um corpo é um corpo", "isso sim é um corpo", "olha esse corpo", "que corpo", "corpo perfeito" e "quero esse corpo", e as palavras "linda", "maravilhosa", "gata" e "perfeita" foram muito utilizadas nos comentários. Isso 
deixa clara a internalização de um ideal especifico de beleza, que é visto como única possibilidade estética e de identidade correta e adequada de ser alcançada.

Outra dimensão abarcada nos comentários dessa categoria diz respeito à beleza corporal como símbolo de divindade e poder. O culto ao corpo magro é explicitado por meio de comentários como: (1) "Ela é diva das divas... maravida total!" (2) "Poderosa e linda!” (3) "Sereia, musa, magraa!!! Arrasani”; (4) "Resumiu a palavra beleza"; (5) "Musa inspiradora", (6) "Affff parece qnão cansa de ser deusa... abusada", (7) “...isso é corpo do poderrrrrrrr" e (8) "Amiga, ela não é uma mulher, ela é uma deusa!!!!”.

As palavras "diva”, "deusa”, "musa”, que foram muito mencionadas nos comentários, emergem de dimensões religiosas, simbolizando divindades que devem ser "cultuadas" e "adoradas", equivalente ao que se observa nos dias atuais em relação ao corpo magro. Destaca-se o comentário de número 8: "Amiga, ela não é uma mulher, ela é uma deusa!!!!”, que traz nas entrelinhas que tal padrão corporal é tão "perfeito e divino" que se distancia das possibilidades corporais dos seres humanos comuns, sendo a personificação da beleza, uma vez que este corpo em especial "resume" o significado dessa palavra. Nesse sentido, as (poucas) pessoas que alcançam esse padrão corporal acabam se convertendo em "divindades inspiradoras", que merecem ser exaltadas e idolatradas. Ao mesmo tempo, a beleza, julgada a partir do ponto de vista estético, causa certa ilusão de que o alcance desse corpo ideal está ao alcance de todos.

Uma análise mais minuciosa dos comentários números 2 ("Poderosa e linda”)e 7 (“...isso é corpo do poderrrrrrrr") remete aos discursos de poder e normatização que permeiam a vida dos sujeitos e afetam seus corpos, identidades e subjetividades. ${ }^{25}$ O corpo desejável, que é fruto de uma construção cultural e sócio-histórica, traz consigo relações de poder. ${ }^{5}$ Para além da beleza, ter um corpo magro, em uma sociedade lipofóbica, se converte em um símbolo desse poder, uma vez que os sujeitos são classificados e qualificados em relação a sua moral e caráter, por seu tamanho corporal. ${ }^{25}$ A pressão cultural para o emagrecimento reforça o sentimento lipofóbico da atualidade.

O discurso lipofóbico da sociedade contemporânea aborda a obesidade não como um corpo que deve emagrecer em benefício da saúde, mas como uma condição corporal sob a qual se encontra um sujeito marcado pelo sofrimento que uma norma lipofóbica impõe. Nesse sentido, percebe-se que o discurso da obesidade como sendo uma doença se consagrou sobretudo pela preocupação com o que era moralmente aceitável, disfarçado sob um discurso de saúde. ${ }^{26}$

Alguns comentários analisados nessa categoria apontam para a preocupação que os seguidores possuem, em relação à composição corporal da blogueira fitness, a aversão de não possuir um corpo esculpido como o dela, e o quanto esses seguidores comparam seu peso ou sua composição corporal amparada nas fotos que são postadas: (1) "Qual o seu percentual de gordura? (Curiosa)"; (2) "Alguém sabe quando de gordura ela tem?"; (3) "Qual seu peso?”; (4) "E eu cada dia mais gorda”. Percebese que saber o peso ou a porcentagem de gordura do corpo visto como "perfeito" é como possuir um parâmetro para se basear, um modelo para seguir. 
Esses comentários também trazem à baila a reflexão acerca da aversão e rejeição ao corpo gordo, que faz parte do contexto sócio-histórico contemporâneo. Uma vez que a aparência magra é considerada como chave do sucesso, o estigma da obesidade se acentua cada vez mais, tomando contornos de deformidade física e moral, e o indivíduo com sobrepeso ou obesidade se torna inteiramente estranho ao universo atual, não sendo mais tolerado socialmente. Toda essa estigmatização do corpo gordo está baseada em um sistema de representações e de crenças, sendo, sem dúvida, uma forma de preconceito socialmente aceitável; os sujeitos com obesidade são os únicos que podem ser discriminados com plena impunidade. ${ }^{2}$

\section{Categoria 2 - "Meu sonho é ter esse corpo": o desejo de metamorfose corporal}

O ambiente sociocultural e a mídia têm forte influência sobre a imagem que o sujeito constrói sobre o próprio corpo e sobre o ideal de corpo que ele gostaria de ter. ${ }^{27} \mathrm{O}$ corpo se torna reflexo da sociedade, da cultura, e é através desse reflexo que constrói suas particularidades, enfatizando determinados atributos em detrimento de outros, criando seus próprios padrões. ${ }^{28}$

Nos dias atuais, o corpo ocupa lugar central nas preocupações cotidianas, e parecemos viver a crise do corpo, onde a necessidade humana de se encaixar neste padrão estético desencadeia uma cascata de sintomas, como o aumento de próteses, novas técnicas cirúrgicas e até mesmo o uso de substâncias químicas. ${ }^{28}$ Comentários como (1) "O corpo que eu queria ter"; (2) "Meta de corpo"; (3) "Super meta da vida!"; (4) "Me dá esse corpo, por favor"; (5) "Quero ficar com o corpo assim”, muito comuns em todas as fotos, externalizam como o corpo vem sendo cada vez mais transformado em máquina, sem sujeitos ou afetos; tornou-se um objeto imperfeito, um rascunho a ser corrigido. ${ }^{29} \mathrm{O}$ corpo deixou de ser identidade de si, e uma forma de ser no mundo, para se transformar em objeto moldável e transitório, uma soma de partes, e qualquer tentativa de mudar o corpo é também uma tentativa de mudar de vida. ${ }^{30} \mathrm{~A}$ imagem corporal representa, cada vez mais, um espelho do self, em que aparência e essência se confundem. ${ }^{19}$ Nesse sentido, o desejo de (re)construção do corpo se confunde com o desejo de (re)construção da própria identidade.

A obtenção do corpo magro/belo exige disciplina e dedicação, um trabalho constante de si para $\mathrm{si}^{19}{ }^{19} \mathrm{o}$ que faz com que o indivíduo comece a disciplinar seu corpo para que se possa obter reconhecimento social e aprovação, estando o prazer associado ao esforço, onde nada é gratuito, tudo é obtido. ${ }^{28} \mathrm{E}$ se você não é capaz de se autodisciplinar, você é o único responsável pelo seu fracasso. $\mathrm{O}$ (re)modelamento e a (re)construção do corpo parecem depender apenas do empenho e esforço individual, como ilustrado pelos seguintes comentários: (1) "Quando vc olha pra esse corpo e pensa que precisa voltar a malhar"; (2) "Haja foco"; (3) "Tá muito lindo esse abdome. Eita disciplina”; (4) "@...pacto fitness até chegar aí”; (5) "Isso é questão de escolha, basta ter coragem e força de vontade, mais nada"; (6) "Precisamos começar a malhar já hahahaha@...", (7) “[...] como se ser fit fosse exclusivamente 
uma questão financeira, os esforços e a dedicação não fossem a parcela maior"; (8) "Qdo crescer, quero ter esse corpitcho!!!! Rsrs... Qdo tiver forças, chego lá!”; (9) "Olha essa barriga amigaaa.... foco e força que conseguimos ela ainda nessa encarnação"; e (10) "Pq uma barriga assim tem que ter muita disciplina!!!Parabéns!!!".

Uma vez que a ideia disseminada é que alcançar o "corpo dos sonhos" é algo que depende, exclusivamente, de força, dedicação, coragem, foco e disciplina, dissemina-se também a ideia de que a falha nesse processo é uma falha pessoal, simbolizando preguiça, fraqueza, incapacidade e descomprometimento. Atribui-se ao indivíduo que se distancia do modelo de corpo estabelecido toda a responsabilidade por sua condição, cabendo também a ele sua solução. ${ }^{3}$

Sob este prisma, o corpo se torna algo gerenciável, um capital-corpo, que orienta escolhas, ordenadas e organizadas segundo determinado fim. E assim pode ser produzido, modulado e ajustado, segundo uma imagem-objetivo definida, a partir de uma variedade de ações produtivas, tecidas estrategicamente. Misturando observação e experimentação, a remodelação do corpo envolve diversas práticas disciplinares, sendo uma delas a atividades física. ${ }^{31}$

É interessante destacar que o "malhar" é frequentemente usado nos comentários, fazendo alusão a como se malha o ferro, (re)modelando, consertando e modificando cada parte. ${ }^{32}$ Nas imagens analisadas, observa-se que o objetivo propagado não gira apenas em torno da magreza, que per si não é mais suficiente; é necessário que o corpo seja também "malhado". A atividade física, que em épocas passadas tinha como objetivo promover o fortalecimento corporal, hoje é realizada principalmente para fins estéticos, com intuito de (re)esculpir o corpo. ${ }^{33}$

A imagem corporal vai sendo construída a partir do contato que o corpo tem com experiências externas, e autoimagem corporal negativa é fonte de grande sofrimento psíquico, gerando baixa autoestima, insegurança, culpa, frustração, ansiedade, depressão e até ideações suicidas. ${ }^{8}$ Alguns comentários exemplificam esse sofrimento, como: (1) "Obrigada, por acabar com a minha autoestima de manhã kkkkkkkkk"; (2) "Tão linda que dá até raiva"; (3) "Pode parar de me humilhar, por favor! \#Linda"; (4) "@...pra eu ter vontade de me matar"; (5) "Se eu entrasse no mesmo voo que vc, e você tivesse vestida assim, com esse corpo eu pulava do avião. Seja sempre muito feliz"; (6) "Como ficar mais depressiva com a vida. Como se já não bastasse tudo"; (7) "Fui cortar os pulsos e já volto!! Hahaha musa"; (8) "Arrasada! Não dou conta..."; (9) "Nem sigo ela pra num querer me matar"; (10) "Aqui de boas me sentindo humilhada com essa barriga", (11) "Pisa menos na minha cara"; e (12) "O corpo que eu nunca vou ter". Os autorretratos contemporâneos, os selfies, se contaminam pelos modelos corporais transmitidos na mídia, e simbolizam o desejo de que o corpo desconhecido seja visualizado e reconhecido. Se a subjetividade não é mais reconhecida como possibilidade de estar no mundo, e o corpo real passa despercebido em vários espaços, a imagem do selfie parece ser um caminho para sair da invisibilidade. Todavia, a distância entre o corpo real e o corpo desejado resulta em percepção de fracasso, insatisfação e sentimentos de inadequação e humilhação. ${ }^{30}$ 
Permeando os sentimentos negativos desses comentários está o entendimento do quão difícil é o alcance desse modelo corporal. O comentário número 12, "O corpo que eu nunca vou ter", sinaliza claramente como esse desejo vem capilarizado da noção da dificuldade em se alcançar esse padrão de corpo, que é distante para a grande maioria da população. Isso porque, além de essa ser uma possibilidade corporal muito restrita e excludente, frente a riqueza da diversidade corporal humana, por vezes esses corpos ideais nem sequer são reais, uma vez que podem ser alterados não apenas com um bisturi em uma cirurgia estética, mas também através do "bisturi digital" - em softwares como o Photoshop. ${ }^{34}$ Deste modo, a estética plástica do corpo ideal vai-se modificando em um movimento contínuo de distanciamento do corpo real e de busca interminável pelo corpo perfeito.

Outra perspectiva abarcada nesta categoria diz respeito ao fenômeno da objetificação corporal em alguns comentários analisados, cujo foco está pautado, exclusivamente, em partes corporais específicas presentes nas fotos, como: (1) "Cinturinhaaaa"; (2) "Uma bunda dessas! Deusa"; (3) "Olha essa barriga"; (4) "Miga tá com um pernão!!!”; (5) "Olha essa panturrilha, essa perna, essa barriga, esse corpo affff! Te amo!"; (6) "Um abdômen é um abdômen”; (7) "Olha a curvinha do músculo da perna”; (8) "Hmmmm poxa que coxaaaaa. rrazồ!"

Imagens de objetificação incluem aquelas que apresentam um indivíduo, comumente mulheres, de maneira que o reduz a um instrumento de prazer ou uso de outros, como imagens que isolam, enfatizam ou avaliam partes corporais específicas, fazendo particular referência a apelo sexual e aparência, desconsiderando quaisquer atributos emocionais ou psicológicos. Quando os indivíduos, sobretudo as mulheres, são socializados para internalizar a perspectiva de um observador como a visão primária de seus próprios físicos, tendem a pensar em si mesmos como objetos a serem vistos, e esse fenômeno é conhecido como auto-objetivação. ${ }^{35}$ Mulheres que experimentam a autoobjetificação adotam a perspectiva de uma terceira pessoa ao se avaliar, levando à preocupação com o automonitoramento e as autoavaliações negativas. E estudos apontam que a exposição a imagens objetivadas, que retratavam o ideal de corpo magro, aumentou os níveis de auto-objetificação, de ansiedade em relação ao peso, de insatisfação corporal e do comer desordenado. ${ }^{36,37}$

\section{Categoria 3 - "Uma escolha errada arruína o corpo inteiro": culpabilização e distorções na relação alimentar}

Os estudos sobre comportamento alimentar nos apresentam um interessante paradoxo, no qual nunca soubemos tanto sobre os efeitos da alimentação sobre o corpo e, ao mesmo tempo, nunca tivemos tantos problemas de saúde relacionados a ela. ${ }^{38}$ Essa "psicopatologia da alimentação cotidiana” é bem ilustrada pelos números atuais de excesso de peso, transtornos alimentares como anorexia e bulimia nervosa, ${ }^{39}$ e desvios do comportamento alimentar ou transtornos dismórficos, como a ortorexia nervosa e a vigorexia nervosa. 
Além disso, observamos uma sobreidentificação dos alimentos acerca de seus constituintes nutricionais, que os reduz de comida a meros nutrientes. Uma farmacologização que suplanta seus aspectos culturais, sociais, simbólicos. O prazer, as preferências e os gostos alimentares estão fora do centro das referências, que privilegia determinadas regras alimentares, pautadas tão somente no papel biológico dos alimentos. Os alimentos são categorizados, de forma bastante simplista, em "bons e maus", "permitidos e proibidos", "saudáveis e não saudáveis", com base apenas em sua composição nutricional: calorias, proteínas, carboidratos, gorduras, fibras, etc., com valorização extrema do seu poder nutritivo, desconsiderando seus demais contornos e significados. Uma verdadeira cultura gastro-anômica. ${ }^{39}$

As pressões sofridas pelo comedor contemporâneo são enormes, exercidas por especialistas e principalmente pela mídia, o que favorece uma situação de "pânico alimentar". A alimentação passa a constituir um campo de decisões pessoais que é alimentado por uma diversidade de normas dissonantes, ${ }^{40}$ dentre as quais se destacam as normas estéticas. Atualmente, existem novos significados atribuídos à alimentação e ao que é considerado "comer bem", frutos da modernidade alimentar, que sintetiza e representa os efeitos que a alimentação tem sofrido frente às transformações sociais. Os alimentos continuam tendo sua função fisiológica, só que eles vêm acompanhados de novas significações ${ }^{40}{ }^{40}$ sendo vistos, principalmente, sob o prisma de um "meio" para construção do corpo perfeito, como se possuíssem elementos mágicos. Frente à supervalorização da alimentação por questões estéticas, não se adequar às normas alimentares, não seguir a "dieta da vez", ou mesmo se permitir ter prazer ao comer, pode causar prejuízos no convívio social e até sensação de não pertencimento em determinados grupos sociais.

Todos esses elementos estão explícitos nos comentários que seguem: (1) “@... bom dia pra você que comeu pizza ontem amiga"; (2) "Acabei de comer uma esfirra que tá pesando na barriga e na consciência...”; (3) "E eu comendo pão de queijo!!! Jamais chegarei nesse corpo”; (4) “@... só de olhar já sofro. Porque ACABEI de comer uma pamonha"; (5) "Aquele momento que vc acaba de bater um prato de lasanha e se arrepende!!!”; (6) “@... acabei de comer x bacon, que triste”; (7) “Acabei de comer uma fileira de milka de oreo, estou chorany"; (8) "Senhor! Livrai nos desse demonho chamado comida!"; (9) "Vem aqui nessa foto quando vc sentir vontade de comer besteira bebê @..."; (10) "Nossa ainda bem q me marcou tava quase comendo um pão"; (11) "Quando eu estiver desistindo da dieta irei olhar essa foto"; e (12) "Tava com vontade de comer um doce! Vi essa foto a vontade passou".

Esses comentários sinalizam uma "patologização do comer", fruto de uma relação distorcida com a comida, na qual marcam presença a culpa, o arrependimento, a necessidade de controle da fome, do prazer e dos desejos alimentares, além de uma forte visão dicotomizada da alimentação. Já não é mais sem culpa o sentar-se à mesa para desfrutar da comida. A alimentação, compreendida aqui como um ato biológico de sobrevivência que considera todo um contexto social, cultural e psicológico, passou a ter, quase que exclusivamente, um caráter curativo para doenças ${ }^{41} \mathrm{e}$, mais atualmente, um caráter modelador ou construtor do corpo desejado, como uma matéria-prima ou 
"um meio para um fim" ${ }^{35}$. Nesse sentido, o ato de se alimentar é reduzido a uma simples prática de medicalização, desconsiderando que, se do ponto de vista biológico temos certas necessidades nutricionais, do ponto de vista sociocultural também temos necessidades a serem preservadas. ${ }^{41}$

Na medida em que comer, alimentar-se, algo que sempre foi tão simples e rotineiro e, ao mesmo tempo, cheio de significados e afetos, foi-se tornando fonte de angústia, confusão, sofrimento e até de julgamento moral, elementos de desidentificação ganham destaque nesse cenário, e quadros de adoecimento mental e físico associados à relação disfuncional com o comer, com a comida e com o corpo, como é o caso dos transtornos alimentares, acabam emergindo. Algumas nuances de sintomas clássicos de transtornos alimentares, como a purgação e o ciclo restrição-compulsão, que são comuns na bulimia nervosa, podem ser vistos em alguns comentários feitos nas fotos: (1) @...vamo vomita a pizza que a gente comeu?”; (2) "Olha a barriga deste ser, cospe a comida que ainda dá tempo"; (3) "Não cospe o almoço, por favor @...”; (4) “@... pensando em vomitar todos os pães de batata que eu ja comi"; (5) "Vomitando o q comi em 3,2,1!!! Poderosaaa”; (6) "Cada dia mais sarada e a gente cada dia com mais fome”; e (7) “@... eu aqui comendo desesperadamente e vejo esse corpo... Fiquei deprimida agora...”

É importante que se tenha um olhar cuidadoso para questões de cunho tão profundo e delicado. A prática de dietas e os comportamentos alimentares desordenados, que podem se iniciar de forma aparentemente "inocente", como uma simples tentativa de perda de peso e de recuperação da autoestima, podem se confundir com preocupação com saúde e mascarar desordens mais graves. E capilarizando todos esses comportamentos alimentares disfuncionais está o corpo, objeto central de insatisfações, visto por meio da preocupação com o peso e da forma física que ele apresenta. ${ }^{42}$ Se imagens de corpos "perfeitos" são cotidianamente veiculadas, e o contato das pessoas com tais imagens é regular e frequente, elas começam a acreditar que é uma versão da realidade, e não alcançar tal ideal é motivo de frustração e insatisfação. ${ }^{43}$ Por sua vez, a insatisfação corporal pode ter como consequências prejuízos no comportamento e atitudes alimentares, sendo um importante gatilho para o desenvolvimento e manutenção de transtornos alimentares. ${ }^{8}$

Evidências na literatura sustentam as relações entre uso de redes sociais e insatisfação corporal, com potenciais repercussões negativas no comportamento alimentar. Alguns autores, verificaram, em estudo feito com adolescentes brasileiras, que o acesso diário maior de dez vezes ao dia ao Facebook e Instagram aumentou a chance de insatisfação corporal em 6,57 e 4,47 vezes, respectivamente. ${ }^{43}$ Outro estudo recente encontrou que seguir contas focadas na aparência e contas de conteúdo fitness ("celebridades") no Instagram esteve associado à internalização do ideal de magreza, à vigilância corporal e ao desejo pela magreza. ${ }^{8}$ Corroborando esses achados, ${ }^{44}$ revisão sistemática sobre o impacto do uso das mídias sociais na insatisfação corporal e no comer transtornado sinalizou algumas atividades problemáticas realizadas nessas redes, como visualização e upload de fotos, que favoreceram a comparação social baseada na aparência, reforçando insatisfação corporal e o comer transtornado. Recente meta-análise também concluiu que a exposição a conteúdo relacionado 
à aparência nas redes sociais se associou a maior preocupação e distúrbios com a autoimagem corporal em mulheres..$^{9}$ Nesse sentido, plataformas cujo foco principal está centrado em fotos/ imagens, como o Instagram, merecem ser mais bem pesquisadas, considerando esse panorama.

\section{Considerações finais}

A busca pelo corpo ideal se tornou uma ideia fixa na contemporaneidade. Os aspectos envolvendo a imagem corporal têm representado a aceitação ou não do indivíduo em diversas esferas da sua vida, podendo ocorrer, inclusive, exclusão social e discriminação caso ele se distancie do padrão exigido. Nesse sentido, faz-se importante compreender que existe uma série de dimensões que perpassam e constituem o corpo - como culturais, sociais e econômicas. Portanto, ele não deve ser reduzido e valorizado exclusivamente por sua dimensão física. Da mesma forma, é fundamental que se compreendam os mecanismos de controle submersos nesses modelos corporais ideais difundidos.

A partir deste estudo, foi possível perceber que o corpo magro é visto como um adereço indispensável para que se possa ser considerado bem-sucedido, realizado, belo e feliz, com associação direta da adequação aos padrões de beleza ao sucesso nas mais variadas dimensões da existência do indivíduo. O corpo a ser visto e consumido simbolicamente age coercivamente sobre aquele que está fora dos padrões. ${ }^{38}$ A partir do entendimento de que, ao conquistar o corpo perfeito, se conquistarão também todos os atributos positivos a ele associados, o desejo de (re)construção do corpo acaba se confundindo com o desejo de (re)construção da própria identidade. Nesse processo, a exigência de se encaixar no corpo belo e magro recai sobre o indivíduo.

A responsabilidade de(re)modelar o corpo se apresenta como dever moral individual, e não de responsabilidade coletiva. ${ }^{38}$ Esta "individualização" do processo de alteração do corpo, centralizando o problema no controle das vontades e desejos, acaba por simplificar algo que é bastante complexo, como se ter \#focoforçaefé fossem o bastante. Uma vez que atingir o tipo físico considerado ideal é impossível para a maioria das pessoas, os sentimentos de frustração, culpa e fracasso são frequentes, gerando grande sofrimento psíquico. ${ }^{8}$ Nesse ínterim, negligencia-se a diversidade de fatores que perpassam a formação dos corpos e seu (re)modelamento, que vão muito além dos esforços individuais.

Foi possível verificar também que o desejo de transformação do corpo ressoa na relação dos indivíduos com a comida, distorcendo-a e gerando uma "patologização do comer". A alimentação passa a ser vista apenas pelo prisma biomédico, como forma de construção do corpo desejado, destacando-se de seu contexto social, cultural, afetivo e simbólico. Isso transforma o ato de comer, antes fonte de prazer e cheio de significados, em algo que gera angústia, arrependimento, culpa e julgamento, que podem agir como gatilhos para o engajamento em dietas restritivas e em comportamentos alimentares desordenados. 
Frente a este cenário, parece fundamental que aprofundemos nossas reflexões acerca da concepção de corpo ideal e das visões simplistas que permeiam tal concepção, que é bastante complexa em sua essência. Os ideais corporais, que são impostos de maneira contundente pelas redes sociais, parecem contaminar nossas noções do que é belo ou feio, como se houvesse apenas dois padrões corporais possíveis: o ideal e o não ideal, sem possibilidades de nuances entre estes extremos. O natural passou a ser rejeitado, e a beleza só é reconhecida quando o indivíduo consegue esculpir seu corpo, seja por meio de atividade física, dieta ou procedimentos cirúrgicos. Os efeitos negativos da insatisfação corporal, como baixa autoestima, depressão e transtornos alimentares, estão diretamente ligados com a saúde mental, bem como com a saúde física do sujeito. À vista disso, é importante que os profissionais de saúde trabalhem as questões corporais a partir das perspectivas de saúde física e mental, fomentando reflexões sobre todas suas pluralidades e singularidades.

\section{Colaboradores}

Silva AFS contribuiu na coleta, análise e interpretação dos dados, elaboração do manuscrito e revisão final; Neves LS contribuiu na coleta, análise e interpretação dos dados e elaboração do manuscrito; Japur CC e Penaforte TR contribuíram na análise e interpretação dos dados, elaboração do manuscrito e revisão final; Penaforte FRO, contribuiu na concepção do estudo, análise e interpretação dos dados, elaboração do manuscrito e revisão final.

\section{Agradecimento}

Agradecimento à Fundação de Amparo à Pesquisa do Estado de Minas Gerais, pela concessão da bolsa de iniciação científica.

\section{Referências}

1. Ribeiro RG, Silva KS, Kruse MHL. O corpo ideal: a pedagogia da mídia. Rev Gaúcha Enferm. 2009; 30(1):71-76.

2. Vigarello G. As metamorfoses do gordo: história da obesidade no Ocidente: da Idade Média ao século XX. Petrópolis: Vozes; 2012.

3. Campos MTA, Cecílio MS, Penaforte FRO. Corpo-vitrine, ser mulher e saúde: produção de sentidos nas capas da Revista Boa Forma. Demetra: Alimentação, Nutrição \& Saúde. 2016; 11(3):611-628.

4. Goffman E. Estigma: Notas sobre a manipulação da identidade deteriorada. Rio de Janeiro: LTC; 1988.

5. Gracia-Arnaiz M. Thou shalt not get fat: medical representations and self-images of obesity in a mediterranean society. Health. 2013; 5(7):1180-1189. 
6. World Health Organization. Obesity and overweight. Geneva: WHO; 2015.

7. Dantas JB. Um ensaio sobre o culto ao corpo na contemporaneidade. Estudos e Pesquisas em Psicologia. 2011; 11(3):898-912.

8. Souza AC, Alvarenga MS. Insatisfação com a imagem corporal em estudantes universitários: Uma revisão integrativa. J Bras Psiquiatr. 2016; 65(3):286-299.

9. Mingoia J, Hutchinson AD, Wilson C, Gleaves DH. The Relationship between social networking site use and the internalization of a thin ideal in females: a meta-analytic review. Frontiers in Psychology. 2017; 8:1-10.

10. Childers TL, Houston MJ. Conditions for a picture-superiority effect on consumer memory. Journal of Consumer Research. 1984; 11(2):643-654

11. Chou H, Edge N. "They are happier and having better lives than I am": the impact of using Facebook on perceptions of others' lives. Cyberpsychology, Behavior, Social Networking. 2012; 15(1):117-120.

12. European Food Information Council 04/2005. Os Determinantes na Escolha dos Alimentos; 2005. [Acesso em: 18 maio 2018]. Disponível em: https://www.eufic.org/en/healthy-living/article/thedeterminants-of-food-choice

13. Liebscher P. Quantity with quality? Teaching quantitative and qualitative methods in a LIS Master's program. Library Trends. 1998; 46(4):668-680.

14. Instagram Help Center. 2015; [acesso em: 20 mai 2017]. Disponível em: https://help.instagram.com.

15. Bardin L. Análise de conteúdo. São Paulo: Edições 70; 2011.

16. Furtado ERG. Representações sociais do corpo, mídia e atitudes [Tese]. [Florianópolis]: Universidade Federal de Santa Catarina; 2009.

17. Goffman E. A representação do eu na vida cotidiana. 14ª ed. Petrópolis: Vozes; 2007.

18. Groesz LM, Levine MP, Murnen SK. The effect of experimental presentation of thin media images on body satisfaction: a meta-analytic review. Int J Eat Disord. 2002; 31(1):1-16.

19. Santos LAS. O corpo, o comer e a comida. Um estudo sobre as práticas corporais e alimentares no mundo contemporâneo. Salvador: EDUFBA; 2008.

20. Campbell C. A ética romântica e o espírito do consumismo moderno. Rio de Janeiro: Rocco; 2001.

21. Ogden J. A vez do Gordo? Desfazendo o mito da dieta. Rio de Janeiro: Imago; 1999.

22. Castro JBP, Mattos RS, Passos MD, Aquino FSD, Retondar JJM, Machado AS. Alimentação, corpo e subjetividades na Educação Física e na Nutrição: o ranço da adiposidade e a ascensão dos músculos. Demetra: Alimentação, Nutrição \& Saúde. 2016; 11(3):803-824.

23. Labre MAMP. Adolescents boys and the muscular male body ideal. Journal of Adolescents Health. 2002; 30(4):233-242.

24. Lima AF, Batista KA, Lara Junior N. A ideologia do corpo feminino perfeito: questões com o real. Psicologia em Estudo. 2013; 18(1):49-59.

25. Gracia-Arnaiz M. Comer bien, comer mal: la medicalización del comportamiento alimentar. Salud Pública de México. 2007; 49(3):236-242. 
26. Seixas CM, Lucena BB. O mundo não é um spa: sobre a ética do desejo na clínica da obesidade In: Prado SD. et al. Estudos socioculturais em alimentação e saúde: saberes em rede. Rio de Janeiro: EDUERJ; 2016. p. 279-296.

27. Schomer EZ, Kachani AT. Imagem corporal. In: Córdas TA, Kachani AT. Nutrição em psiquiatria. Porto Alegre: Artmed; 2010.

28. Barbosa MR, Matos PM, Costa ME. Um olhar sobre o corpo: o corpo ontem e hoje. Psicologia \& Sociedade. 2011; 23(1):24-34.

29. Breton DL. O corpo supranumerário no espaço cibernético. In: Breton DL. Adeus ao corpo: antropologia e sociedade. São Paulo: Papirus; 2003.

30. Campos SS, Ferreira FR, Seixas CM, Wollz LEB. Gordinha da Silva: análise discursiva acerca do corpo feminino considerado gordo no universo dos blogs. Demetra: Alimentação, Nutrição \& Saúde. 2016; 11(3):629-642.

31. Wacquant L. Corpo e alma. Notas de um aprendiz de boxe. Rio de Janeiro: Relume-Dumará; 2002.

32. Ulian MD, Gualano B, Benatti FB, Campos-Ferraz PL, Roble OJ, Modesto BT, et al. Eu tenho um corpo gordo, e agora? Relatos de mulheres obesas que participaram de uma intervenção não prescritiva, multidisciplinar e baseada na abordagem "Health at Every Size. Demetra: Alimentação, Nutrição \& Saúde. 2016; 11(3):697-722.

33. Nascimento DE, Afonso MR. Os corpos na sociedade contemporânea. EFDeportes.com, Revista Digital. 2014; 18(190). [acesso em: 14 fev. 2017]. Disponível em: http://www.efdeportes.com/efd190/ os-corpos-na-sociedade-contemporanea.htm

34. Mabe AG, Forney KJ, Keel PK. Do you "like" my photo? Facebook use maintains eating disorder risk. Int. J. Eat. Disord. 2014; 47:516-523.

35. Fredrickson BL, Roberts T. Objectification theory: toward understanding women's lived experiences and mental health risks. Psychology of Women Quarterly. 1997; 21(2):173-206.

36. Harper B, Tiggemann M. The effect of thin ideal media images on women's self-objectification, mood, and body image. Sex Roles. 2008; 58:649-657.

37. Murnen SK, Smolak L, Mills JA, Good L. Thin, sexy women and strong, muscular men: gradeschool children's responses to objectified images of women and men. Sex Roles. 2003; 49:427-437.

38. Medeiros M, Galeno A. Olhares sobre a alimentação contemporânea: a gastro-anomia e os corpos de Botero. Rev Nutr. 2013; 26(4):465-472.

39. Goldenberg M. Cultura e gastro-anomia: psicopatologia da alimentação cotidiana entrevista com claudefischler. Horizontes Antropológicos. 2011; 36:235-256.

40. Fonseca A, Souza TSN, Frozi DS, Pereira, RS. Modernidade alimentar e consumo de alimentos: contribuições sócio-antropológicas para a pesquisa em nutrição. Ciênc Saúde Coletiva. 2011; 16(9):3853-3862.

41. Garcia RWD. Representações sociais da alimentação e saúde e suas repercussões no comportamento alimentar. PhYSIS - Revista de Saúde Coletiva. 1997; 7(2):51-68. 
42. Carvalho RS, Amaral ACS, Ferreira MEC. Transtornos alimentares e imagem corporal na adolescência: uma análise da produção cientifica em psicologia. Psicologia: Teoria e Prática. 2009; 11(3):200-223.

43. Lira AG, Ganen AP, Lodi AS, Alvarenga MS. Uso de redes sociais, influência da mídia e insatisfação com a imagem corporal de adolescentes brasileiras. J Bras Psiquiatr. 2017; 66(3):164-171.

44. Holland G, Tiggemann M. A systematic review of the impact of the use of social networking sites on body image and disordered eating outcomes. BodyImage. 2016; 17:100-110.

Recebido: 23 de março de 2018

Revisado: 12 de maio de 2018

Aceito: 24 de maio de 2018 
